\title{
De Varsovia a Montreal y de Montreal a Varsovia: cuestionamientos judiciales a la incorporación al derecho nacional del Convenio de Montreal, referido al transporte aéreo internacional
}

\author{
Fernando Hurtado de Mendoza Pomar ${ }^{*}{ }^{*}$
}

Resumen.- A raíz de una casación de la Corte Suprema que aplicó el Convenio de Varsovia sobre el Convenio de Montreal, el autor describe la evolución del marco legal aplicable a la responsabilidad derivada del transporte aéreo internacional en los tratados ratificados por el Perú. Asimismo, critica los fundamentos de la referida casación, defendiendo la aplicación del Convenio de Montreal ante determinados supuestos, y expone las posibles consecuencias negativas de este pronunciamiento judicial.

Abstract.- As a consequence of a Supreme Court's ruling that enforces the Warsaw Convention over the Montreal Convention, the author describes the evolution of the legal framework regarding international air carrier liability in the treaties ratified by Peru. Likewise, the author criticizes the arguments on which the ruling relies, defending the enforcement of the Montreal Convention before certain scenarios, and details the possible negative consequences of said judicial decision. Law. 


\section{Introducción}

En el Perú, el marco legal aplicable para determinar la responsabilidad civil de los transportistas aéreos está recogido en la Ley de Aeronáutica Civil y su reglamento. Con relación a vuelos internacionales, dicha norma nos remite al régimen de responsabilidad establecido en los tratados ratificados por el país. En efecto, según el artículo 264 del Reglamento de la Ley de Aeronáutica Civil, en el transporte aéreo internacional de pasajeros, equipaje y carga, la responsabilidad del transportista se rige por los instrumentos internacionales vigentes para el Perú. En tal sentido, el tratado que en la actualidad recoge la principal regulación aplicable a la responsabilidad derivada del transporte aéreo internacional, en el Perú y en otros 123 países ${ }^{1}$, es el Convenio para la unificación de ciertas reglas para el transporte aéreo internacional hecho en Montreal el 28 de mayo de 1999, más conocido como el Convenio de Montreal. ${ }^{2}$

En general, el Convenio de Montreal establece las reglas aplicables a la responsabilidad derivada de los daños ocasionados a los usuarios con quienes el transportista haya suscrito un contrato de transporte aéreo. De este modo regula, entre otros aspectos, las indemnizaciones que deberá pagar el transportista en caso de que un pasajero sufra lesiones o fallezca como consecuencia de un accidente, así como en caso de que el equipaje facturado del pasajero, su equipaje de mano o la carga transportada se deteriore o destruya durante la operación aérea. Asimismo, prevé topes máximos a estas indemnizaciones, los supuestos en los que estos límites pueden superarse y los casos en los cuales el transportista puede eximirse de su responsabilidad. Por último, establece también la manera en que los usuarios afectados podrán iniciar reclamos al amparo del tratado.

A pesar de haber entrado en vigor el 4 de noviembre de 2003 luego de su ratificación mediante el Decreto Supremo No 026-2002-RE, una peculiar casación emitida por la Corte Suprema inaplicó el Convenio de Montreal para un caso que resolvía el reclamo de una aseguradora local ante dos (2) operadores aéreos extranjeros por la carga dañada y perdida en dos (2) vuelos realizados en el año 2004 entre una ciudad asiática y Lima. El argumento de la Corte Suprema consistió en que el Convenio de Montreal solo había sido

1 Cabe indicar que la Unión Europea también es parte del Convenio de Montreal en su calidad de sucesora de la Comunidad Europea, la cual se adhirió a dicho convenio en 2004.

2 Existen otros tratados que regulan la responsabilidad del transportista aéreo en ámbitos distintos que los previstos por el Convenio de Montreal, como el Convenio sobre indemnización por daños causados a terceros por aeronaves, al cual el Perú no se ha adherido. 
ratificado por el Presidente del Perú, cuando conforme a la Constitución debió haber sido también aprobado por el Congreso de la República por ser un tratado que exigía la modificación o derogación de una ley. La supuesta ley cuya modificación o derogación se exigía era el Convenio de Varsovia, el tratado que el Convenio de Montreal tuvo como objetivo uniformizar y modernizar.

En virtud de dicho razonamiento, el régimen legal de responsabilidad aplicable al caso fue el recogido en el Convenio de Varsovia y no el contenido en el Convenio de Montreal. Esta decisión judicial reabre la discusión sobre la posición que tienen los tratados dentro de la legislación nacional. Resulta obligatorio, pues, discutir las formalidades locales que deben seguirse respecto de las convenciones internacionales y comparar los regímenes en el transporte aéreo internacional al amparo del Convenio de Montreal y de su predecesor, el Convenio de Varsovia. Ciertamente, el hecho de que esta decisión aislada de la Corte Suprema se convierta en un referente judicial podría tener una serie de implicancias prácticas en el transporte aéreo para los pasajeros que toman vuelos internacionales y en la reputación de la República del Perú con relación al cumplimiento de sus obligaciones internacionales.

\section{El Sistema de Varsovia y el Convenio de Montreal}

Tanto el Convenio de Montreal como el Convenio de Varsovia tuvieron como objetivo uniformizar las reglas del transporte aéreo relativas a la responsabilidad del transportista, además de las concernientes a los documentos de viaje. No obstante, cuando se ideó el Convenio de Varsovia no existía ningún cuerpo normativo que reuniera dichas reglas, mientras que con la gestación del Convenio de Montreal se buscó uniformizar las distintas reglas que ya habían sido establecidas por el Convenio de Varsovia y sus distintos protocolos.

Por otra parte, el Convenio de Montreal persiguió modernizar las disposiciones previstas en el Convenio de Varsovia. Por ello, la regulación de la responsabilidad del transportista aéreo en virtud de ambos tratados dista de ser la misma. Así, el Convenio de Varsovia tuvo como principal intención proteger una incipiente industria aérea, mientras que el Convenio de Montreal enfatizó la búsqueda de indemnizaciones equitativas a favor de los pasajeros que sufrieran daños como consecuencia del transporte aéreo.

\section{i. El Sistema de Varsovia}

El Convenio de Varsovia fue firmado en dicha ciudad el 12 de octubre de 1929. 
A la fecha, 152 países lo han ratificado o se han adherido a él ${ }^{3}$, incluyendo al Perú que se adhirió al convenio mediante la Resolución Legislativa № 24819. En virtud de esta resolución, el Perú se adhirió además al Protocolo de la Haya (1955), al Convenio de Guadalajara (1961) ${ }^{4}$ y a los Protocolos Adicionales $N^{\circ} 1$ y N ${ }^{\circ} 2$ de Montreal (1975). El Convenio de Varsovia, el Protocolo de la Haya y el Convenio de Guadalajara se ratificaron mediante el instrumento de adhesión del 14 de junio de 19885, mientras que los Protocolos Adicionales $\mathrm{N}^{\circ}$ 1 y N 2 de Montreal se ratificaron mediante el Decreto Supremo N 024-97RE.

Adicionalmente, mediante la Resolución Legislativa $N^{\circ} 30041$ y el Decreto Supremo N 027-2013-RE se aprobó y ratificó el Protocolo Adicional Nº 3 de Montreal (1975) y mediante la Resolución Legislativa $N^{\circ} 30042$ y el Decreto Supremo N 028-2013-RE se aprobó y ratificó el Protocolo Adicional N 4 de Montreal (1975). Por último, mediante la Resolución Legislativa Nº 30067 y el Decreto Supremo $N^{\circ}$ 045-2013-RE se aprobó y ratificó el Protocolo de Guatemala (1971) ${ }^{6}$. De los anteriores, únicamente el Protocolo Adicional $N^{\circ} 4$ de Montreal entró en vigor al haber alcanzado, a diferencia de los demás, la cantidad mínima de ratificaciones previstas. Todos estos convenios y protocolos en conjunto conforman el Sistema de Varsovia.

El Convenio de Varsovia fue concebido entre la Primera y la Segunda Guerra Mundial, cuando la industria del transporte aéreo era incipiente. Por ello, su principal fundamento consistió en la protección de las aerolíneas, a fin de fomentar el desarrollo de este mercado. Dicho objetivo se refleja en sus disposiciones, entre las cuales destacan los límites máximos de indemnización, las exoneraciones de responsabilidad y las jurisdicciones competentes ante posibles reclamos. Asimismo, se regulan en un solo instrumento las normas sobre la responsabilidad del transportista y los documentos del transporte aéreo en busca de uniformidad en un intento por reducir los problemas

3 Existen siete (7) países que no ratificaron o se adhirieron al Convenio de Varsovia, pero que ratificaron o se adhirieron al Protocolo de la Haya que lo modifica; por lo que indirectamente se adhirieron al referido convenio. Según el artículo 23 del Protocolo de La Haya, la ratificación o adhesión a este protocolo por países que no hayan ratificado el Convenio de Varsovia, o que no se hayan adherido a este, implica la adhesión al Convenio de Varsovia.

4 El Convenio de Guadalajara extendió las reglas del Convenio de Varsovia al transportista de hecho, es decir, a aquel que realiza el transporte a pesar de no haber suscrito el respectivo contrato.

5 Según información publicada en el Archivo Nacional de Tratados Embajador Juan Miguel Bákula Patiño de la Dirección General de Tratados del Ministerio de Relaciones Exteriores de la República del Perú.

6 El Protocolo de Guatemala buscó actualizar las reglas concernientes al transporte de pasajeros y equipaje. Posteriormente, algunas de sus disposiciones fueron incorporadas en el Protocolo Adicional $N^{\circ} 3$ de Montreal. 
De Varsovia a Montreal y de Montreal a Varsovia: cuestionamientos judiciales a la incorporación al derecho nacional del Convenio de Montreal, referido al transporte aéreo internacional

derivados de los conflictos de leyes.7

Con arreglo a su artículo 1, el Convenio de Varsovia es aplicable a todo transporte internacional a título oneroso de personas, equipajes o mercancías realizado en aeronaves. Se entiende por "transporte internacional" a todo transporte que se inicia y termina en el territorio de partes contratantes del convenio, o el transporte que se inicia o termina en el territorio de una parte contratante, siempre y cuando haya una escala de por medio en cualquier otro país, sin importar que este país sea parte contratante del tratado. Tal como precisa el artículo 1 del referido convenio, el transporte realizado entre territorios de la misma parte contratante, sin que medie dicha escala, no será considerado como "transporte internacional".

De conformidad con los artículos 17 y 18 del referido convenio, el transportista es responsable del daño ocasionado por muerte, lesión o cualquier otra lesión corporal sufrida por cualquier pasajero, cuando el accidente que cause el daño se haya producido a bordo de la aeronave o durante las operaciones de embarque y desembarque. Asimismo, el transportista es responsable del daño ocasionado por la destrucción, pérdida o avería (deterioro) de equipajes facturados o de mercancías (carga), cuando el hecho que cause el daño se haya producido durante el transporte aéreo, entendido como el período durante el cual los equipajes o las mercancías se hallen bajo la custodia del transportista ${ }^{8}$.

El artículo 22 del Convenio de Varsovia establece que en el transporte de personas la responsabilidad del transportista se limita a 125,000 francos franceses (aproximadamente US\$ 8,300). El límite descrito implica que, en caso de responsabilidad, el transportista deberá pagar sumas no muy elevadas con relación a los daños que podría haber generado por muerte o lesión del pasajero. De acuerdo con Jennifer McKay, estas sumas resultan de muy poco valor cuando se les compara con las indemnizaciones que los tribunales

7 "El propósito de la Convención de Varsovia fue unificar el derecho internacional con relación a los operadores aéreos y a suplantar las leyes domésticas de cada nación miembro si ellas diferían de los términos de la Convención [...] La Convención busca limitar la posible responsabilidad de los operadores aéreos en caso de accidentes, facilitar prontas recuperaciones a los pasajeros, unificar leyes en los países parte del tratado y establecer uniformidad de documentos". GOLDHIRSCH, Lawrence B. The Warsaw Convention Annotated: A Legal Handbook. La Haya: Kluwer Law International, 2000, p. 5.

Traducción libre de: "The purpose of the Warsaw Convention was to unify international law with respect to air carriers and to supplant each member nation's domestic laws if they differed from the terms of the Convention [...] The Convention seeks to limit international air carriers' potential liability in case of accidents, facilitate speedy recoveries by passengers, unify laws in treaty countries and establish uniformity of documents".

8 A pesar de que los referidos artículos 17 y 18 del Convenio de Varsovia no contemplan la responsabilidad del transportista por el daño ocasionado por la destrucción, pérdida o avería de los objetos personales de los pasajeros, del artículo 22 del convenio se desprende que el transportista será responsable por estos daños hasta un límite de 5,000 francos franceses (aproximadamente US\$330) por pasajero. 
pueden otorgar al presentárseles casos de transporte aéreo doméstico. Sin duda esto fue regulado de dicha forma para proteger a la industria aérea, evitando así el pago de sumas indemnizatorias más elevadas ${ }^{9}$.

“La posición es, sin embargo, totalmente diferente con la muerte o lesiones de un pasajero. La mayoría de los pasajeros no son conscientes de la existencia del límite, y mucho menos de su monto. Pocos se encuentran asegurados o debidamente asegurados"10.

Ante la presión internacional que replicaba estas críticas, el límite de responsabilidad en el transporte de personas fue ampliado a 250,000 francos franceses (aproximadamente US\$ 16,600) mediante el Protocolo de La Haya. Luego, los Protocoles Adicionales $\mathrm{N}^{\circ} 1$ y $\mathrm{N}^{\circ} 2$ de Montreal modificaron la manera de cuantificar la indemnización de francos franceses a Derechos Especiales de Giro (DEG) ${ }^{11}$ y establecieron nuevos límites: primero 8,300 DEG (aproximadamente US\$11,500) y luego 16,600 DEG (US\$23,000). No obstante, estas sumas muchas veces no han llegado a satisfacer la reparación de los daños, más aún cuando el transportista puede eximirse de su responsabilidad conforme al artículo 20 del Convenio de Varsovia.

El referido artículo 20 del Convenio de Varsovia establece que el transportista no es responsable de los daños si prueba que él y sus dependientes tomaron todas las medidas necesarias para evitar el daño, o que les fue imposible tomarlas. Nuevamente, se trata de una disposición dirigida a proteger a los transportistas, pues les permite eximirse de toda responsabilidad si demuestran encontrarse en alguno de los supuestos mencionados. Es decir, bajo el convenio en mención el transportista siempre tiene la posibilidad de eximirse del daño causado. Por otra parte, de acuerdo con el mismo artículo, la responsabilidad del transportista puede atenuarse o descartarse si prueba que la persona lesionada ha sido causante del daño o ha contribuido al mismo.

9 Cfr. MCKAY, Jennifer. “The refinement of the Warsaw system: why the 1999 Montreal Convention represents the best hope for uniformity". En Case Western Reserve Journal of International Law, Vol. 34, $\mathrm{N}^{\circ} 1,2002$, p. 79.

10 CHENG, Bin. "A new era in the law of international carriage by air: from Warsaw (1929) to Montreal (1999)”. En International and Comparative Law Quarterly, Vol. 53. N 4, 2004, p. 835.

Traducción libre de: "The position is, however, totally different with passenger death or injury. Most passengers are unaware of the existence of the limit, and still less its actual amount. Few are insured or adequately insured".

11 De acuerdo con información publicada por el Fondo Monetario Internacional (FMI), el Derecho Especial de Giro es un activo de reserva internacional creado en 1969 por el propio FMI para complementar las reservas oficiales de los países miembros y se puede intercambiar por monedas de libre uso. A partir del 1 de octubre de 2016, el valor del DEG se basa en una cesta de cinco (5) monedas principales: el dólar estadounidense, el euro, el renminbi chino, el yen japonés y la libra esterlina. 
Por otra parte, el artículo 28 del Convenio de Varsovia prescribe que la acción de responsabilidad debe presentarse, a elección del demandante -el usuario afectado- en el territorio de una de las partes contratantes del tratado, entre las siguientes opciones de tribunales: (i) el del domicilio del transportista; (ii) el del domicilio de la oficina del transportista; (iii) el del lugar donde el transportista posea un establecimiento por cuyo conducto haya sido celebrado el contrato; o, (iv) el del lugar de destino. En consecuencia, si el usuario afectado no domicilia en el territorio de alguno de los tribunales descritos, se encontrará con severas dificultades para demandar el resarcimiento de sus daños al no existir la posibilidad expresa de demandar en los tribunales de su propio domicilio.

\section{ii. La transición entre ambos sistemas}

Los topes indemnizatorios insuficientes, la posibilidad del transportista de eximirse de su responsabilidad y la dificultad del usuario afectado para demandar el resarcimiento de sus daños constituyeron el primer motivo por el cual, tras múltiples intentos para modificar el Convenio de Varsovia reflejados en sus protocolos, negociaciones y diversos acuerdos privados, se ideó el Convenio de Montreal para reemplazar al Sistema de Varsovia. Debe señalarse que un elemento que facilitó la transición hacia el Convenio de Montreal fue la evolución favorable de la industria aérea, pues se consideraba que ya no requería de las medidas proteccionistas concedidas cuando se creó el Convenio de Varsovia.

De hecho, el preámbulo del Convenio de Montreal reconoce expresamente "la importancia de asegurar la protección de los intereses de los usuarios del transporte aéreo internacional y la necesidad de una indemnización equitativa fundada en el principio de restitución".

“Antes de la introducción del Convenio de Montreal, los límites resarcitorios permanecieron generalmente bajos, en línea con las primeras filosofías dirigidas a apoyar a la industria naciente. La industria, a pesar de los desafíos de hoy en día, ha evolucionado significativamente con respecto a su estabilidad comercial y a ciertos estándares de seguridad. Acuerdos comerciales, como acuerdos entre transportistas aéreos, acuerdos de código compartido y acuerdos de alianzas aéreas, y la compleja naturaleza del comercio internacional han ocasionado prácticas imprevistas por los redactores de las primeras convenciones, tales como documentación electrónica en lugar de los boletos tradicionales de papel y guías aéreas" 12 .

12 BARTSCH, Ronald I. C. International Aviation Law: A Practical Guide. Ashgate: Surrey, 2012, p. 
Una segunda razón que motivó la gestación del Convenio de Montreal fue la existencia de diversos cuerpos normativos que se superponen unos a otros dentro del Sistema de Varsovia, no siempre ratificados por las partes o a los cuales las partes contratantes no siempre se han adherido: el Protocolo de la Haya, y los Protocolos Adicionales $\mathrm{N}^{\circ} 1, \mathrm{~N}^{\circ} 2$ y $\mathrm{N}^{\circ} 4$ de Montreal, y ciertos acuerdos privados destinados a corregir algunas deficiencias en el sistema identificadas por los Estados y por los propios transportistas. Esta falta de uniformidad deriva en un régimen jurídico enredado, cuyas consecuencias resultan difíciles de determinar tanto para los transportistas como para los pasajeros y demás usuarios del transporte aéreo al no conocer con precisión las normas jurídicas aplicables ${ }^{13}$.

“El Convenio de Montreal evolucionó del Convenio de Varsovia original, diversos Protocolos y un Convenio Complementario, el cual modificó el Convenio original en la mayoría de países. Este nuevo Convenio también adoptó, en principio, las disposiciones sobre la responsabilidad respecto de los pasajeros previstas en el Acuerdo entre Transportistas Aéreos de la IATA de 1995-1996 celebrado por los operadores aéreos renunciando a los límites de responsabilidad previstos en el Convenio de Varsovia con respecto a los pasajeros.

El Convenio de Montreal es esencialmente una mezcla del Convenio de Varsovia, diversos Protocolos, el Convenio Complementario y los Acuerdos entre Transportistas de la IATA"14.

65.

Traducción libre de: "Prior to the introduction of the Montreal Convention, compensation limits remained generally low, in line with the early philosophies aimed at supporting a fledgling industry. The industry, despite present-day challenges, has developed significantly in respect of its commercial stability and relative safety standards. Commercial arrangements such as inter-carrier, code-shares and airline alliance agreements, and the complex nature of international trade have led to practices never envisaged by the drafters of earlier conventions, such as electronic documentation in place of traditional paper tickets and air waybills".

13 Según McKay, otras fuentes de la falta de uniformidad son las diferentes interpretaciones lingüísticas del Convenio de Varsovia (siendo el francés su único idioma original), las diferentes interpretaciones por los tribunales domésticos del Sistema de Varsovia, la conversión de las indemnizaciones prescritas a monedas locales y el cálculo del plazo prescriptorio. Cfr. MCKAY, Jennifer. "The refinement of the Warsaw system: why the 1999 Montreal Convention represents the best hope for uniformity". En Case Western Reserve Journal of International Law. Vol. 34. N 1. pp. 90-93.

14 WHALEN, Thomas J. "The new Warsaw Convention: the Montreal Convention". En Air $\mathcal{E}$ Space E Law, Vol. 25, N¹, 2000, p. 12.

Traducción libre de: "The Montreal Convention evolved from the original Warsaw Convention, several Protocols and a Supplementary Convention which amended the original Convention in most countries. This new Convention also adopted, in principle, the passenger liability provisions of the 1995-1996 International Air Transport Association (IATA) Intercarrier Agreements entered into by airlines waiving the passenger limits of liability of the Warsaw Convention.

The Montreal Convention is essentially a composite of the Warsaw Convention, several Protocols, the 


\section{iii. El Convenio de Montreal}

Los principales cuestionamientos al Sistema de Varsovia han tratado de ser superados en el Convenio de Montreal, siendo el caso que este último mantiene el mismo ámbito de aplicación que el Convenio de Varsovia. En la actualidad, se está más cerca de una regulación equitativa para ambas partes el transportista y los pasajeros-, a diferencia de la situación establecida por el Convenio de Varsovia y sus normas posteriores ${ }^{15}$. Seguidamente, se analizarán las disposiciones previstas en el Convenio de Montreal con relación a los topes indemnizatorios insuficientes, la posibilidad del transportista de eximirse de su responsabilidad y la dificultad del usuario afectado para demandar el resarcimiento de sus daños.

Conforme a los artículos 16, 17 y 18 del Convenio de Montreal, tal como ocurre con el Convenio de Varsovia, el transportista continúa siendo responsable del daño causado en caso de muerte o de lesión corporal de un pasajero, así como del daño ocasionado por la destrucción, pérdida o avería del equipaje facturado, de los objetos personales y de la carga. No obstante, y a diferencia de los límites máximos de indemnización establecidos por el Sistema de Varsovia por daños por muerte o lesiones del pasajero -que se fueron elevando progresivamente de 125,000 a 250,000 francos franceses, luego a 8,300 DEG y finalmente a 16,600 DEG de conformidad con los diversos protocolos del Convenio de Varsovia-, no existe un tope máximo inquebrantable en el Convenio de Montreal para tales daños.

Por otra parte, se recuerda que al amparo del Convenio de Varsovia es posible que el transportista exima su responsabilidad por el total de los daños infligidos, si prueba que él y sus dependientes habían tomado todas las medidas necesarias para evitar el daño o que les fue imposible tomarlas. No obstante, el Convenio de Montreal opera bajo un régimen de responsabilidad distinto mediante el cual, a diferencia del convenio anterior, el transportista ya no se puede eximir de responsabilidad por el íntegro de los daños, sino únicamente a partir de cierta suma al haberse establecido un sistema de dos tramos de responsabilidad.

En efecto, con relación a los daños por muerte y lesiones corporales del pasajero, el artículo 21 del Convenio de Montreal prescribe que el transportista no podrá excluir ni limitar su responsabilidad por los primeros 100,000 DEG

Supplementary Convention and the IATA Intercarrier Agreements".

15 Como se verá en la siguiente sección en la que se analizará el pronunciamiento judicial de la Corte Suprema que inspiró el presente artículo, esta regulación más equitativa frente a los pasajeros contenida en el Convenio de Montreal no significa que algunas disposiciones referidas a otros usuarios del transporte aéreo internacional contenidas en el Sistema de Varsovia no sean más favorables que las recogidas en el Convenio de Montreal. 
(aproximadamente US\$138,500) por pasajero. Únicamente cuando los daños ocasionados superen tal suma el transportista podrá eximirse de responsabilidad por el monto que la exceda en los siguientes casos: (i) cuando pruebe que el daño no se debió a la negligencia o a otra acción u omisión indebida del transportista o sus dependientes o agentes; o, (ii) cuando pruebe que el daño se debió únicamente a la negligencia o a otra acción u omisión de un tercero.

Algunos autores consideran que el aumento de los límites máximos de indemnización no es una innovación propia del Convenio de Montreal, sino que este aspecto ya venía siendo desarrollado por diversos acuerdos privados, como el Acuerdo de Montreal de 1966 o los Acuerdos de la IATA de 199616/17. No obstante, a pesar de que el Convenio de Montreal no haya sido el impulsor original de dicho cambio, resulta sumamente plausible el hecho de que lo haya codificado en un instrumento propio del derecho internacional público. Precisamente por ello esta medida tiene mayor alcance al haber sido ratificado por un elevado número de países y no solo por operadores aéreos de manera privada.

Por último, cabe recordar que conforme al Convenio de Varsovia son cuatro (4) las posibles jurisdicciones ante las cuales se pueden iniciar reclamos derivados

16 El Acuerdo de Montreal de 1966 se gestó como consecuencia de la intención de los Estados Unidos de América de denunciar el Convenio de Varsovia debido a sus bajos límites indemnizatorios. En respuesta, los propios transportistas aumentaron el límite de su responsabilidad a US\$ 75,000 para los vuelos que tengan como punto de partida, destino o escala a los Estados Unidos de América. Por otra parte, en virtud de los Acuerdos de la IATA de 1996, los transportistas renunciaron a sus defensas para reclamos hasta por un monto de 100,000 DEG.

17 Cfr. FIELD, Andrew. "Air travel, accidents and injuries: why the new Montreal Convention is already outdated". En Dalhousie Law Journal, Vol. 28, No 1, 2005, p. 77. Al respecto: "El Artículo 21 representa un gran avance en las disposiciones del Convenio de Varsovia. No obstante, si representa tal avance sustantivo en los derechos de los pasajeros en la práctica es quizás otro tema. Discutiblemente, la realidad no es tan impresionante como la apariencia. Esto es por que por lo menos desde 1966 los límites prescritos en el Convenio de Varsovia han sido revertidos por una serie de acuerdos privados y reformas legislativas [...] El punto que está siendo ilustrado aquí es que, en muchos casos, los muy alardeados incrementos en los límites en el Convenio de Montreal son solo un reflejo de una realidad que ya existe. En efecto, notando que desde 1998 más de cien operadores aéreos han suscrito los Acuerdos entre Transportistas Aéreos de la IATA de la década de 1990, es justo decir que ello ha tenido más que ver con el incremento de los límites de responsabilidad que el Convenio de Montreal".

Traducción libre de: "Article 21 represents a great advance on the provisions of the Warsaw Convention. However, whether it represents such a great advance on the substance of passengers' rights in practice is perhaps another matter. Arguably, the reality is not quite as impressive as the appearance. This is because since at least 1966 the limits set down in Warsaw Convention have been rolled back by a series of private agreements and legislative reforms [...] The point being illustrated here is that in many cases, the much vaunted increase of liability limits in the Montreal Convention is merely a case of mirroring a reality which already exists. Indeed, noting that in 1998 over one hundred carriers had signed the IATA Intercarrier Agreements of the 1990s, it is fair to say that they have had more to do with increasing liability limits than the Montreal Convention". 
del tratado, sin incluirse de manera expresa la jurisdicción del territorio donde domicilia el demandante. Por ello, si ninguna de las posibles jurisdicciones de acuerdo con el Convenio de Varsovia es la de su país de domicilio, el usuario tiene graves inconvenientes y altos desincentivos para demandar a fin de hacer valer sus derechos. A diferencia de su antecesor, el Convenio de Montreal permite expresamente que un pasajero pueda demandar en su país de domicilio, siempre y cuando se cumplan los parámetros indicados en este convenio.

En tal sentido, de acuerdo con el artículo 33 del Convenio de Montreal una de las jurisdicciones ante la cual también se podrá iniciar la acción de indemnización -únicamente con relación a los daños por muerte o lesiones del pasajero- es la de los tribunales ubicados en el territorio en el que el pasajero tiene su residencia principal y permanente en el momento del accidente y hacia, y desde el cual, el transportista explota servicios de transporte aéreo de pasajeros en sus propias aeronaves o en las de otro transportista con arreglo a un acuerdo comercial. Asimismo, es necesario que el transportista realice sus actividades de transporte aéreo de pasajeros desde locales arrendados o que sean de su propiedad o de otro transportista con el que tiene un acuerdo comercial en dicho territorio.

El establecimiento de esta quinta jurisdicción no está ausente de críticas. Una de ellas indica que el único objetivo de esta medida propuesta por los Estados Unidos de América consiste en proteger los intereses de los pasajeros estadounidenses, de modo que ellos puedan demandar fácilmente en su propio país. Por otra parte, se argumenta que con las cuatro (4) jurisdicciones anteriores los pasajeros ya estaban suficientemente protegidos. Sin embargo, conforme lo explica Devendra Pradhan a pesar de que inicialmente esta disposición haya estado orientada a favorecer solo a un pequeño grupo de pasajeros, la nueva jurisdicción establece una protección adicional a favor de todos ellos, quienes ahora podrán demandar con mayor facilidad ${ }^{18}$.

La inexistencia de máximos indemnizatorios insuperables, la limitada posibilidad del transportista de eximirse de su responsabilidad y la mayor facilidad del pasajero para demandar en su lugar de domicilio son los pilares que erigen al Convenio de Montreal como un tratado destinado a favorecer los intereses de los pasajeros. A diferencia del Convenio de Varsovia, el nuevo tratado ya no responde únicamente a proteger a la industria aérea, sino que busca resarcir los daños de los pasajeros mediante indemnizaciones equitativas. Del mismo modo, este convenio ha logrado agrupar y modernizar

18 Cfr. PRADHAN, Devendra. "The fifth jurisdiction under the Montreal liability Convention: wandering American or wandering everybody?". En Journal of Air Law and Commerce, Vol. 68, $\mathrm{N}^{\circ} 4,2003$, p. 725. 
en un solo cuerpo normativo disposiciones que se encontraban anteriormente dispersas y así ha dotado de mayor predictibilidad al sistema y de seguridad jurídica a los pasajeros.

\section{El pronunciamiento de la Corte Suprema sobre la aplicación del Convenio de Montreal}

\section{i. Los hechos y el análisis de la Corte Suprema}

La sucursal peruana de una empresa transnacional especializada en electrónica, cuya aseguradora es una empresa de seguros local, adquirió diversas cámaras digitales de video y memorias USB en el extranjero. Estas mercancías fueron transportadas por dos operadores aéreos extranjeros desde una ciudad asiática hacia Lima mediante dos (2) vuelos llevados a cabo en el año 2004. Tras la llegada de ambos vuelos, se determinó que faltaban cinco (5) memorias USB y que siete (7) cámaras digitales de video se habían dañado y que otras dos (2) cámaras se habían perdido. Los daños ascendían a US\$ $7,057.14$. Esta última suma fue demandada por la empresa aseguradora a los operadores aéreos en la vía judicial tras haberse subrogado en los derechos de la sucursal, luego de haber efectuado el pago de dicha suma a su favor.

La demanda fue declarada fundada en el año 2010 y se ordenó de manera solidaria a los operadores aéreos extranjeros el pago de US\$ 7,057.14 a favor de la aseguradora local -la totalidad de los daños alegados-, aplicando el Convenio de Varsovia. Los operadores aéreos apelaron la sentencia invocando la equivocada aplicación del Convenio de Varsovia, ya que consideraban que el Convenio de Montreal era el instrumento aplicable al caso ${ }^{19}$. La Corte Superior confirmó en el año 2011 parte de la sentencia apelada, reformando el extremo que ordenaba el pago de US\$ 7,057.14 y disponiendo que se pague el equivalente a 17 DEG (aproximadamente US\$24) por cada kilogramo de peso

19 El argumento principal utilizado por el juez de primera instancia para aplicar el Sistema de Varsovia en lugar del Convenio de Montreal consistió en el mayor rango que dentro del derecho nacional tendría el Sistema de Varsovia frente al Convenio de Montreal, toda vez que el Convenio de Montreal fue ratificado por el Presidente de la República por medio de un decreto supremo -con rango de reglamento-, mientras que el Sistema de Varsovia fue aprobado por resoluciones legislativas -con rango de ley-. Por lo tanto, en el ordenamiento jurídico nacional el Convenio de Montreal no podría modificar al Sistema de Varsovia por contar con una menor jerarquía normativa. Este planteamiento, además de partir de una premisa equivocada ya que el Convenio de Montreal no modifica al Sistema de Varsovia (conforme se explicará a continuación), ha sido superado ampliamente por la doctrina. Así, las formalidades escogidas para incorporar un tratado al derecho nacional -tales como los decretos supremos o las resoluciones legislativas- son independientes al rango de ley que poseen los tratados en el derecho nacional.

Cfr. NOVAK, Fabián; SALMÓN, Elizabeth. Las obligaciones internacionales del Perú en materia de derechos humanos. Segunda edición. Fondo Editorial de la Pontificia Universidad Católica del Perú: Lima, 2000, pp. 116-126. 
por las pérdidas y daños registrados, de acuerdo con el Convenio de Montreal. El valor en moneda nacional se determinaría en ejecución de sentencia.

La diferencia entre ambas sentencias se deriva de las distintas disposiciones que contiene cada uno de los tratados en cuestión. Así, el artículo 9 del Convenio de Varsovia, modificado por el artículo 7 del Protocolo de la Haya, señala que para el caso de mercancías embarcadas sin que se haya expedido una carta de porte aéreo el transportista no puede ampararse en los límites de responsabilidad previstos en dicho convenio. En cambio, para el mismo supuesto, el artículo 9 del Convenio de Montreal indica que los límites de responsabilidad continuarán aplicándose. Esta cuestión resulta de suma importancia para el presente caso puesto que se discutía en el proceso civil que los operadores aéreos no habían emitido la guía aérea que ampare el transporte de la carga.

Tanto bajo el Sistema de Varsovia, como al amparo del Convenio de Montreal, el límite de responsabilidad por daños a la carga es de 17 DEG por cada kilogramo de carga. No obstante, en caso de que no se haya expedido la carta de porte aéreo, el límite previsto en el Sistema de Varsovia no sería aplicable, a diferencia del límite establecido en el Convenio de Montreal, el cual sí lo sería. Sobre la base de estas diferencias, la aplicación del Convenio de Varsovia favorecía a la empresa de seguros al cubrir la totalidad de su pretensión monetaria, mientras que la aplicación del Convenio de Montreal beneficiaba a los operadores aéreos pues limitaba el monto a indemnizar.

Sin perjuicio del pronunciamiento a su favor, los operadores aéreos interpusieron recurso de casación contra la sentencia antes mencionada argumentando que la Corte Superior debió determinar la cantidad de kilogramos de carga dañada y perdida a partir de las pruebas aportadas por las partes, al no poder resolverse esta cuestión en ejecución de sentencia ${ }^{20}$. Mediante la Casación N 1607-2012 del Callao, la Corte Suprema declaró fundado el recurso de casación y ordenó que la Corte Superior emita una nueva sentencia de conformidad con los considerandos establecidos. De este modo, la Corte Superior rectificó su omisión y, en función del peso de la carga pérdida y dañada, ordenó el pago de 307 DEG (aproximadamente US\$430) en aplicación del Convenio de Montreal.

Como era de esperarse, la empresa de seguros interpuso recurso de casación contra la última sentencia emitida por la Corte Superior debido a la aplicación indebida del Convenio de Montreal. Mediante la Casación N 1008-2015 del Callao que inspiró la elaboración del presente artículo, la Corte Suprema

20 Conforme a los operadores aéreos, en esta última etapa únicamente podía practicarse la conversión de DEG a moneda nacional. 
declaró fundado el recurso de casación, declaró nula la sentencia casada de segunda instancia y confirmó la sentencia apelada de primera instancia que ordenó el pago de US\$ 7,057.14 bajo la aplicación del Convenio de Varsovia. En opinión de la Corte Suprema, no era aplicable al caso el Convenio de Montreal debido a los siguientes motivos:

“Décimo Tercero: Que, en tal sentido, se aprecia en primer término que como regla general el Presidente de la República puede celebrar o ratificar tratados o adherir a estos, sin que exista como requisito previo la aprobación del Congreso de la República, siendo la excepción aquellos casos [entre otros] en que los tratados exigen la modificación o derogación de alguna ley.

Décimo Cuarto: Que, en el presente caso, el Convenio de Varsovia de 1929 modificado por el Protocolo de la Haya de 1955 [ambos aprobados por el Congreso de la República del Perú en 1988] tiene rango de ley conforme a lo establecido en el artículo 200 inciso 4 de la Constitución Política del Estado en concordancia con el artículo 55 del mismo cuerpo normativo; por lo que el Convenio de Montreal de 1999 al modificar disposiciones contenidas en el primer Convenio acotado, referidas a las sanciones aplicables al transportista internacional por pérdidas o averías de equipaje y mercancías, debió ser aprobado por el Congreso de nuestro país de acuerdo a los artículos 56 y 57 de la Constitución Política del Perú, lo cual no sucedió, siendo únicamente ratificado por el Presidente de la República en el año dos mil dos.

Décimo Quinto: Que, en consecuencia, el Convenio de Montreal del veintiocho de mayo de mil novecientos noventa y nueve, no resulta válido y constitucional, y por tanto tampoco aplicable al caso de autos, encontrándose conforme a la ley la decisión de la Juez de la causa respecto al monto que las demandadas deben pagar de forma solidaria a la demandante".

En síntesis, la Corte Suprema indica que, conforme al artículo 200 de la Constitución, los tratados tienen rango de ley dentro del ordenamiento jurídico nacional. En efecto, dicho artículo atribuye indirectamente rango de ley a los tratados, pues prescribe que la demanda de inconstitucionalidad procede ante normas con rango de ley, enumerando entre ellas a los tratados: "Son garantías constitucionales: [...] 4. La Acción de Inconstitucionalidad, que procede contra las normas que tienen rango de ley: leyes, decretos legislativos, decretos de urgencia, tratados, reglamentos del Congreso, normas regionales de carácter general y ordenanzas municipales que contravengan la Constitución en la forma o en el fondo".

Teniendo en cuenta lo dispuesto por el artículo 56 de la Constitución, deben ser aprobados por el Congreso de la República, entre otros, los tratados que 
exigen modificación o derogación de alguna ley21. En tal sentido, la Corte Suprema considera que el Convenio de Montreal, en tanto modifica o "deroga"22 al Convenio de Varsovia modificado por sus diversos protocolos los cuales cuentan con rango de ley en virtud del referido artículo 200 de la Constitución-, debió ser aprobado por el Congreso, y no solo ratificado por el Presidente de la República del Perú. Por tales motivos, el Convenio de Montreal no resulta válido ni constitucional, y mucho menos aplicable al caso concreto.

\section{ii. Análisis del pronunciamiento de la Corte Suprema}

En nuestra opinión, el pronunciamiento de la Corte Suprema es incorrecto por las razones que se mencionan a continuación y se desarrollarán en los siguientes párrafos. Primero, porque el Convenio de Montreal no modifica ni "deroga" al Convenio de Varsovia, como lo señala la Corte Suprema. Segundo, porque la regla de que el Congreso de la República debe aprobar previamente los tratados que exijan la modificación o derogación de alguna ley está referida únicamente a la modificación y derogación de leyes internas, y no a ajustes referidos a tratados con rango de ley. Tercero, porque para la ratificación del Convenio de Montreal no es necesario modificar ni derogar ley alguna dentro del derecho interno.

En primer lugar, el Convenio de Montreal no modifica ni "deroga" al Convenio de Varsovia ni a ninguno de sus protocolos: únicamente prevalece sobre el Sistema de Varsovia, el cual en determinados supuestos mantiene su plena vigencia y aplicación. De acuerdo con el artículo 55 del Convenio de Montreal, este prevalecerá sobre toda regla de transporte aéreo internacional entre los Estados parte del Convenio de Montreal, incluyendo al Convenio de Varsovia, al Protocolo de la Haya y a los Protocolos Adicionales $N^{\circ} 1, \mathrm{~N}^{\circ} 2$ y $\mathrm{N}^{\circ} 4$ de Montreal23. Es decir, el Convenio de Montreal será el que se aplicará entre los

21 Según el artículo 56 de la Constitución, una serie de tratados deben ser aprobados por el Congreso antes de su ratificación por el Presidente de la República: aquellos que versen sobre derechos humanos; soberanía, dominio o integridad del Estado; defensa nacional; obligaciones financieras del Estado; los que crean, modifican o suprimen tributos; los que exigen modificación o derogación de alguna ley; y los que requieren medidas legislativas para su ejecución. De otro lado, el artículo 57 de la Constitución establece que el Presidente podrá ratificar, sin la aprobación previa del Congreso, todos los tratados que no versen sobre alguna de las materias contempladas por el artículo 56 de la Constitución, con excepción de los tratados que afecten disposiciones constitucionales. En tal sentido, cuando el tratado afecte disposiciones constitucionales, deberá ser aprobado por el mismo procedimiento que rige la reforma de la Constitución, antes de ser ratificado por el Presidente de la República, conforme al artículo 57 de la Constitución.

22 A pesar de lo dicho por la Corte Suprema, los tratados no se "derogan", sino que se denuncian, conforme se explicará seguidamente.

23 Artículo 55 del Convenio de Montreal.-

El presente Convenio prevalecerá sobre toda regla que se aplique al transporte aéreo 
Estados parte, aun cuando estos mismos Estados sean parte de algún instrumento del Sistema de Varsovia.

"Sin embargo, es importante notar que la supremacía del Convenio de Montreal sobre otros acuerdos previos aplica solo a aquellos países que han ratificado el nuevo Convenio. Si un país declina ratificar el nuevo acuerdo, y continúa adherido a alguno de los tratados anteriores, el Convenio de Montreal no aplicará a los viajes hacia y desde dicho país" 24 .

En consecuencia, cuando se trate de un vuelo entre un Estado parte del Convenio de Montreal -como el Perú- y un Estado que no haya ratificado o se haya adherido al Convenio de Montreal pero sí al Convenio de Varsovia -del cual el Perú es también parte-, el Convenio de Varsovia y sus respectivos protocolos serán los instrumentos aplicables. Por lo tanto, la ratificación del Convenio de Montreal no implica ni la modificación ni la "derogación" del Convenio de Varsovia o de alguno de sus protocolos, sino que se trata de tratados sucesivos concernientes a la misma materia. De hecho, estos siguen formando parte del derecho nacional al no haber sido denunciados por el Presidente del Perú25.

internacional:

1. entre los Estados Partes en el presente Convenio debido a que esos Estados son comúnmente Partes de

a) el Convenio para la unificación de ciertas reglas relativas al transporte aéreo internacional firmado en Varsovia el 12 de octubre de 1929;

b) el Protocolo que modifica el Convenio para la unificación de ciertas reglas relativas al transporte aéreo internacional firmado en Varsovia el 12 de octubre de 1929, hecho en La Haya, el 28 de septiembre de 1995;

c) el Convenio, complementario del Convenio de Varsovia, para la unificación de ciertas reglas relativas al transporte aéreo internacional realizado por quien no sea el transportista contractual firmado en Guadalajara el 18 de septiembre de 1961;

d) el Protocolo que modifica el Convenio para la unificación de ciertas reglas relativas al transporte aéreo internacional firmado en Varsovia, el 12 de octubre de 1929 modificado por el Protocolo hecho en La Haya el 28 de septiembre de 1955, firmado en la ciudad de Guatemala el 8 de marzo de 1971;

e) los Protocolos adicionales núm. 1 a 3 y el Protocolo de Montreal núm. 4 que modifica el Convenio de Varsovia modificado por el Protocolo de La Haya o el Convenio de Varsovia modificado por el Protocolo de La Haya y el Protocolo de la ciudad de Guatemala firmado en Montreal el 25 de septiembre de 1975.

2. dentro del territorio de cualquier Estado Parte en el presente Convenio debido a que ese Estado Parte en uno o más de los instrumentos mencionados en los apartados a) y e) anteriores.

24 MCKAY, Jennifer. "The refinement of the Warsaw system: why the 1999 Montreal Convention represents the best hope for uniformity". En Case Western Reserve Journal of International Law, Vol. 34, $\mathrm{N}^{\circ} 1$, p. 87.

Traducción libre de: "However, it is important to note that the Montreal Convention's supremacy over previous agreements applies only to those countries that actually ratify the new Convention. If a country declines to ratify the new agreement, and continues to adhere to one of the older treaties, the Montreal Convention will not apply to travel to and from that country".

25 Sobre el particular, cabe señalar que lo dispuesto por el artículo 55 del Convenio de Montreal 
Más aún, bajo la lógica de la Corte Suprema se estaría ante un caso de supuesta derogación del Convenio de Varsovia por el Convenio de Montreal. Como se recuerda, esto no ha sucedido; sin embargo, permite ver con claridad el error en la pretendida aplicación a la relación de sucesión entre normas internacionales de una norma constitucional referida a cuestiones de mero orden interno. Ciertamente, equiparar la afectación a una norma de puro orden interno a la afectación de una norma que ratifica un tratado, e imponerles a ambos casos el requisito de aprobación congresal, conllevaría implícitamente a que se considere que el Congreso de la Republica tendría una atribución sobre la denuncia de los tratados 26 , cuando conforme al artículo 57 de la Constitución la denuncia de los tratados es potestad del Presidente de la República.

En segundo lugar, aun en el caso de que el Convenio de Montreal haya modificado al Convenio de Varsovia, la regla prevista en el artículo 56 de la Constitución relativa a la aprobación previa del Congreso de los tratados que exijan la modificación o derogación de alguna ley está destinada a adaptar el derecho interno a los tratados que suscriba un Estado. En tal sentido, únicamente deberá requerirse la aprobación del Congreso de la República con respecto a esta regla cuando se exija la modificación de una ley interna, y no de un tratado con rango de ley. Por ello, incluso en caso de que el Convenio de Montreal hubiese modificado al Convenio de Varsovia no se requeriría de la aprobación congresal.

La necesidad de que los tratados descritos en el artículo 56 de la Constitución sean aprobados por el Congreso de manera previa a su ratificación por el Presidente de la República se basa en que tales clases de tratados se encuentran relacionados con la potestad legislativa, la cual constitucionalmente recae en el Congreso ${ }^{27}$. En particular, la aprobación previa del Congreso cuando el tratado

no ha estado exento de críticas. Como se recuerda, un problema que el Convenio de Montreal busca resolver es la superposición de los diversos cuerpos normativos que conforman el Sistema de Varsovia. No obstante, Bin Cheng argumenta que con la inclusión del artículo 55 en los términos en los que está redactado no se resuelve, sino que se acentúa, dicho problema al sumarse un cuerpo normativo más. Por ello, Cheng lamenta que no haya existido una disposición en el Convenio de Montreal que obligue a denunciar los tratados que forman parte del Sistema de Varsovia como originalmente había sido propuesto por el Reino Unido con la finalidad de resolver este problema.

Cfr. CHENG, Bin. "A new era in the law of international carriage by air: from Warsaw (1929) to Montreal (1999)". En International and Comparative Law Quarterly, Vol. 53, N 4, 2004, pp. 857-859.

26 Cabe recordar que los tratados no se "derogan", lo cual por sí solo deja en evidencia que hay una incorrección técnica en el razonamiento de la Corte Suprema en el caso bajo comentario, puesto que ello deja en evidencia que la norma constitucional en la que basa su posición no se puede referir a afectaciones a normas que ratifican tratados.

27 "Si leemos el artículo 56 de la Constitución, nos damos cuenta que las materias reservadas al Congreso en relación a los tratados, son precisamente las que tienen que ver con las normas legislativas de rango de ley que es, precisamente, el conjunto de disposiciones que deben dictarse con ejercicio de la potestad legislativa". RUBIO, Marcial. Estudio de la Constitución Política del Perú de 1993. Tomo III. 
exija la modificación o derogación de alguna ley está orientada exclusivamente a la adecuación de las leyes internas. "La aprobación del congreso se hace entonces necesaria en la medida que debe existir coordinación entre las normas internas que aprueba el congreso y los tratados internacionales que impliquen la modificación o derogación de tales normas" 28.

Por ello, debe tenerse presente que la ratificación de un tratado que modifica a otro tratado -como sería el caso de una modificación por medio de un protocolo- no está supeditada a la aprobación por parte del Congreso de la República. A pesar de que el artículo 56 de la Constitución se refiera a la modificación o derogación de "alguna ley" y que los tratados tengan rango de ley en el Perú, no existe adecuación alguna que deba hacerse a la legislación nacional. Por consiguiente, un tratado que será modificado no calza dentro del ámbito de aplicación del artículo 56 de la Constitución, pues la aprobación previa del Congreso cuando el tratado exija la modificación o derogación de alguna ley está orientada exclusivamente a la adecuación de leyes internas, y no a la de tratados con rango de ley.

En tercer lugar, para ratificar el Convenio de Montreal no se requirió en ningún momento de la modificación o derogación de ninguna norma de orden interno. Como se recuerda, el artículo 264 del Reglamento de la Ley de Aeronáutica Civil prescribe que, en el transporte aéreo internacional de pasajeros, equipaje y carga, la responsabilidad del transportista se rige por los instrumentos internacionales vigentes para el Perú. Asimismo, de acuerdo con el artículo 81.3 de la Ley de Aeronáutica Civil, se entiende por "servicio de transporte aéreo internacional" el realizado entre el territorio peruano y el de un Estado extranjero o entre dos puntos del territorio peruano cuando exista una o más escalas intermedias en el territorio de un Estado extranjero.

Así, la legislación peruana se remite expresamente a los tratados celebrados por el Perú para regular la responsabilidad derivada del transporte aéreo internacional. En tanto la definición de transporte aéreo internacional, tal como se define en las leyes peruanas, coincide con el ámbito de aplicación del Convenio de Montreal, no existe necesidad alguna de adaptar el derecho interno peruano para que este guarde coherencia con el Convenio de Montreal. Por lo anterior, nunca se requirió la aprobación del Congreso de la República, puesto que para ratificar el Convenio de Montreal no se exigió la modificación

Primera edición. Fondo Editorial de la Pontificia Universidad Católica del Perú: Lima, 1999, p. 157.

28 NOVAK, Fabián. “La regulación de los tratados en la Constitución peruana de 1993”. En Ius et Veritas, $N^{\circ} 17,1998$, pp. 262-263. 
o derogación de ninguna norma de orden interno ${ }^{29}$.

En todo caso, en el plano internacional los Estados están obligados a cumplir con el derecho internacional al margen de lo que dicten sus disposiciones internas. Así, el artículo 27 de la Convención de Viena sobre el derecho de los tratados, de la cual el Perú es parte, establece que una parte no podrá invocar las disposiciones de su derecho interno como justificación del incumplimiento de un tratado, sin perjuicio de lo dispuesto en el artículo 46 de la referida convención. En consecuencia, en caso de que se considere que el Perú no ha incorporado adecuadamente el Convenio de Montreal a su derecho interno, deberá aplicarlo de todos modos. De lo contrario, el Perú incumpliría sus obligaciones asumidas internacionalmente.

"Por ende, si una nueva ley, o una modificación a una ley existente, es necesaria para hacer cumplir las obligaciones de un Estado cuando brinda su consentimiento al tratado, un Estado negociador deberá asegurarse de que esto esté hecho por lo menos antes de que el tratado entre en vigor para aquel. Si esto no está hecho, no solo el Estado estará en riesgo de incumplir sus obligaciones conforme al tratado, sino que también será responsable de acuerdo con el derecho internacional frente a otra parte si, como resultado, dicha parte, o sus nacionales, sufren daños más adelante" 30 .

La única excepción a este precepto es el artículo 46 de la referida Convención de Viena. Este indica que el hecho de que el consentimiento de un Estado para obligarse por un tratado haya estado en violación de una disposición de su derecho interno concerniente a la competencia para celebrar tratados solo podrá ser alegado por dicho Estado como vicio de su consentimiento cuando dicha violación sea manifiesta y afecte a una norma de importancia fundamental de su derecho interno. En nuestra opinión, la aprobación congresal no fue requerida por los motivos antes indicados, por lo que sería contraproducente para la República del Perú en el plano internacional desconocer la vigencia y plena eficacia del Convenio de Montreal.

\section{Conclusiones}

29 Al respecto, la Ley de Aeronáutica Civil entró en vigor el 11 de mayo de 2000, mientras que su reglamento entró en vigor el 21 de diciembre de 2001. Ambas fechas son anteriores a la fecha de entrada en vigor del Convenio de Montreal para el Perú.

30 AUST, Anthony. Modern treaty law and practice. Tercera edición. Cambridge University Press: Cambridge, 2013, p. 161.

Traducción libre de: "Thus, if a new law, or a modification to existing law, is needed in order to carry out the obligations on the state by the time it consents to be bound by the treaty, a negotiating state should ensure that this is done at least by the time that the treaty enters into force for it. If this is not done, not only will the state risk being in breach of its treaty obligations, but it will also be liable in international law to another party if, as a result, that party, or its nationals, is later damaged". 
El Convenio de Varsovia fue concebido con la intención de proteger a la industria aérea con la finalidad de fomentar su desarrollo, así como de uniformizar las normas relativas a los documentos del transporte aéreo. Entre sus principales disposiciones resaltan el establecimiento de topes indemnizatorios, la posibilidad del transportista de eximirse de toda responsabilidad y la dificultad del pasajero afectado de demandar de acuerdo con las circunstancias del caso en su propio lugar de domicilio. A través de sus diversos protocolos, el Convenio de Varsovia intentó revertir la excesiva protección a los transportistas, lo cual se logró finalmente por medio de la entrada en vigor del Convenio de Montreal.

El Convenio de Montreal representa la modernización del Convenio de Varsovia. A diferencia de este último, el Convenio de Montreal fue gestado para proteger en mayor medida los intereses de los pasajeros. En virtud de este objetivo, se aumentaron los montos indemnizatorios a los pasajeros en caso de accidentes aéreos, se eliminaron los límites de indemnización, se limitó la posibilidad del transportista de exonerarse de su responsabilidad y se facilitó que el pasajero pueda demandar en su lugar de domicilio. Asimismo, se unificaron en un solo cuerpo normativo las diversas normas sobre la responsabilidad derivada del transporte aéreo que se encontraban dispersas en los distintos cuerpos normativos que conforman el Sistema de Varsovia.

No obstante, el pronunciamiento de la Corte Suprema analizado amenaza el desarrollo alcanzado en el Perú con relación a la responsabilidad en el transporte aéreo internacional al establecer que el Convenio de Montreal ha sido incorporado defectuosamente al derecho nacional. En nuestra opinión, este pronunciamiento es incorrecto pues se basa en un errado entendimiento de la relación de prevalencia entre el Sistema de Varsovia y el Convenio de Montreal, así como en una equivocada interpretación del artículo 56 de la Constitución. En realidad, el Convenio de Montreal ha seguido los procedimientos internos necesarios para su ratificación, por lo que su aplicación por los órganos jurisdiccionales resulta plenamente exigible.

El desconocimiento de la Corte Suprema acerca del procedimiento de incorporación de tratados al derecho interno podría tener efectos que trasciendan a la aseguradora local y a los transportistas aéreos en disputa en el caso bajo comentario. La difusión de este precepto equivocado que resulta en la aplicación del Sistema de Varsovia por encima del Convenio de Montreal constituye un peligroso precedente que podría afectar los intereses de los pasajeros y, ulteriormente, el continuo desarrollo de la industria aérea. Asimismo, la inaplicación del Convenio de Montreal podría conducir a que se determine que el Perú ha incumplido sus obligaciones internacionales y la 
De Varsovia a Montreal y de Montreal a Varsovia: cuestionamientos judiciales a la incorporación al derecho nacional del Convenio de Montreal, referido al transporte aéreo internacional

responsabilidad a la cual estaría sujeto el Estado peruano por dicha inejecución. 